\title{
OBSERVATIONS CONCERNING THE CLINICAL AND METABOLIC EFFECTS OF CORTICOSTERONE (COMPOUND B) IN RHEUMATOID ARTHRITIS ${ }^{1}$
}

\author{
By WILLIAM S. CLARK, JOSEPH A. BLAIS, AND WALTER BAUER
}

\begin{abstract}
(From the Medical Clinic, Massachusetts General Hospital; the Department of Medicine, Harvard Medical School; and the Massachusetts Department of Public Health)
\end{abstract}

(Submitted for publication March 30, 1953; accepted April 17, 1953)

Corticosterone is a naturally occurring adrenal corticosteroid which has been isolated from adrenal gland extracts $(1,2)$, adrenal perfusates $(3,4)$ and adrenal vein blood (5). Biosynthesis has made this steroid available for clinical studies. It has been demonstrated to influence carbohydrate, nitrogen, and electrolyte metabolism $(6,7)$, but to be devoid of antirheumatic effects (8). These studies were undertaken to investigate further its metabolic and antirheumatic properties.

\section{PROCEDURE}

Corticosterone was administered by mouth in doses of 100 milligrams every 8 hours for 8 days to one patient with typical, moderately severe rheumatoid arthritis. All treatment was discontinued prior to the experiment with the exception of 20 hours bed rest per day and active bed exercises twice daily. Subjective changes in the arthritis were determined daily by questioning the patient on the degree of fatigue, weakness, aching, stiffness, soreness, and pain at rest. Objective changes were determined daily by inspection and palpation of the involved structures by two observers. Balance studies were performed on constant diet and fluid intake by methods described by Reifenstein, Albright, and Wells (9). Stools were collected in four-day periods, and urines in two-day periods. Oral arterial and venous glucose tolerance tests were carried out during the control period and at the termination of treatment.

Case summary. The patient, a 34 year old male (MGH No. 717532), had enjoyed good health until twenty-seven months before admission, when he developed pain and stiffness of the temporomandibular joints. These symptoms subsided within two weeks. He remained well until twenty-three months before entry, when he developed pain, stiffness, and swelling of the elbows, wrists, fingers, knees, and ankles. His symptoms remained constant until fifteen months before entry, when pain in the hips,

1 This publication No. 143 of the Robert W. Lovett Memorial Foundation for the study of crippling disease, Harvard Medical School. The expenses of the investigation were defrayed in part by a grant from the Commonwealth Fund. shoulders, and cervical spine increased. He had had no chills, fever, cardiac, gastro-intestinal or genito-urinary symptoms. He had had anorexia, weight loss of ten pounds, moderate fatigue, and persistent conjunctivitis.

One year before this study, he was given 150 milligrams of hydrocortisone acetate daily for eight days. At the completion of treatment, he was asymptomatic except for mild aching of both shoulders. However, slight to moderate thickening of both elbows and the right wrist remained. He continued unchanged for seven days after treatment, but on the eighth day pain reappeared. Relapse was complete at the end of four weeks. Nine months before entry he was treated with intramuscular cortisone acetate under identical conditions as hydrocortisone acetate and with similar results. Complete relapse again appeared in four weeks, and his condition remained unchanged to the present study.

Physical examination revealed a thin, tense man with prominent eyes and bilateral pterygii. His temperature was $98.6^{\circ}$ F. and blood pressure, 140/90. A grade I apical systolic murmur was present, but cardiac size and rhythm were normal. The liver and spleen were not palpable. A few small lymph nodes were palpable in the axillae.

Examination of the joints revealed slight restriction of motion of the temporomandibular joints and cervical spine. The proximal phalangeal joints of all fingers and the second and third metacarpo-phalangeal joints bilaterally were tender and swollen with small effusions. Both wrists were swollen and tender. The elbows were warm, tender, and swollen with effusions. The fingers, wrists and elbows were limited in motion. The shoulders had normal, but painful, passive motion. The lower extremities were normal except for slight thickening of the knees, limitation of dorsi-flexion of the ankles, and tenderness of the metatarso-phalangeal joints. Small subcutaneous nodules were present over both upper ulnae and both lateral malleoli. Muscle atrophy was pronounced about the shoulder girdles and in the forearms and thighs.

Laboratory findings on admission consisted of a normal urinalysis, a hemoglobin of 16 grams per cent, and total white blood count of 8,500. X-ray examinations of the hands, elbows, shoulders, knees, ankles, and feet showed the bones to be well mineralized. There was some soft tissue thickening about the proximal phalangeal joints. Small cystic areas of rarefaction were seen in some of the carpal bones. 


\section{METHODS}

The following methods were used : sodium and potassium -flame photometer (10), chloride-Wilson and Ball (11), nitrogen-Pregl (12), calcium-Fiske and Logan (13), phosphorus-Fiske and Subbarow (14), 17 ketosteroids-Nathanson and Wilson (15), sedimentation rate -Rourke and Ernstene (16), serum glucose-Nelson (17), eosinophils-Randolph (18).

\section{RESULTS}

\section{Clinical Results}

The changes in the arthritis starting with the control period are shown in Figure 1 by the follow- ing scheme. The precontrol base-line is given a value of 100 per cent activity. Shaded areas above this line indicate increased activity, and clear areas below this line, improvement.

The patient remained afebrile throughout the experiment. On the third hospital day aspirin (3 grams per day) was discontinued. During the next three days there was a moderate increase in pain, stiffness, fatigue, and anorexia. A slight increase in swelling of the midphalangeal joints occurred. Symptoms and signs remained constant until the nineteenth hospital day, that is, two days before starting corticosterone, when pain and stiff-
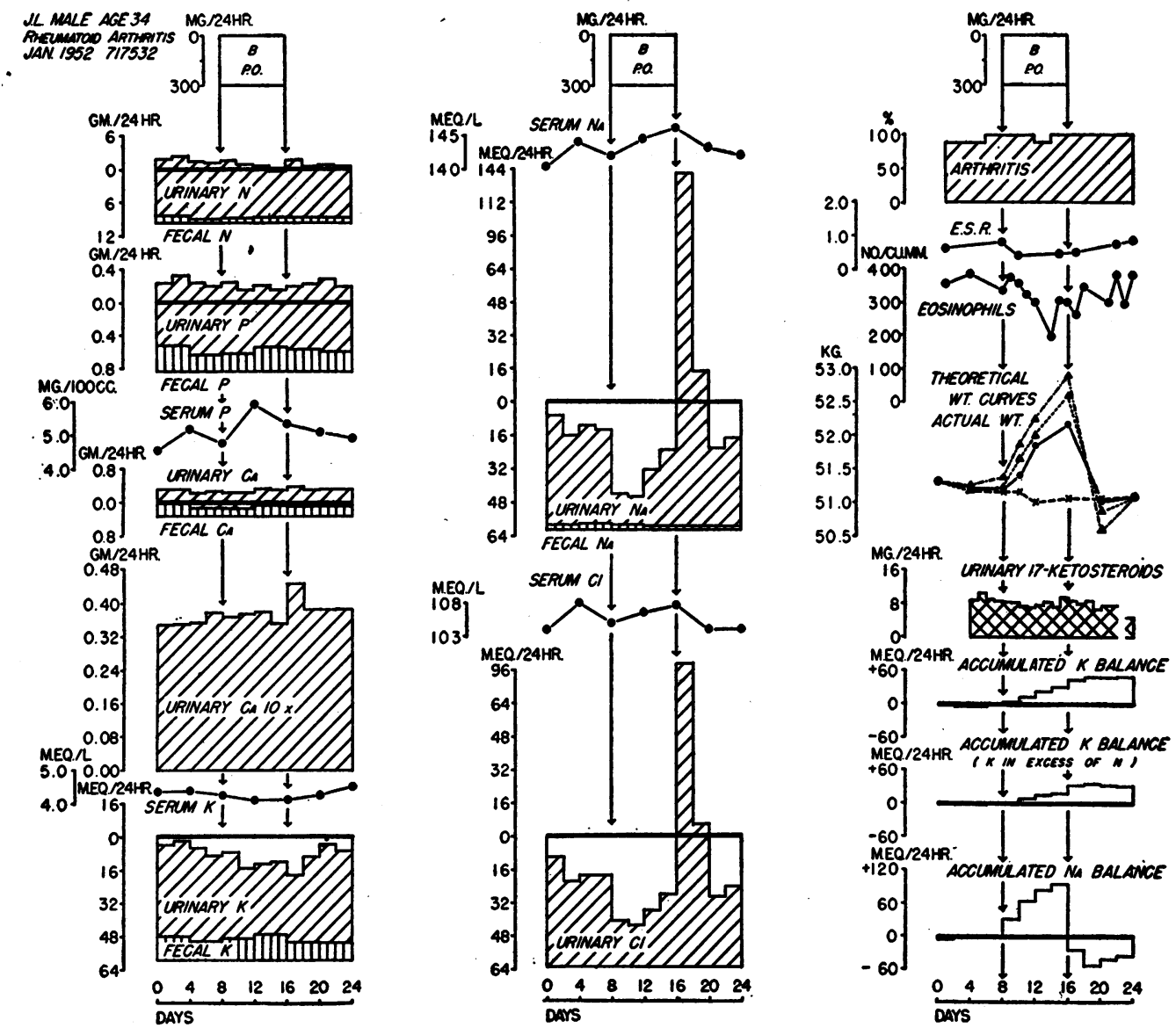

FIG. 1

The first column indicates balance data and serum values for nitrogen, phosphorus, calcium, and potassium and urinary calcium. The second column indicates balances and serum values for sodium and urinary chlorides. The third column indicates the clinical course, sedimentation rates, circulating eosinophils, urinary $\mathbf{1 7}$ ketosteroids, and cumulative sodium and potassium balances, including potassium corrected for nitrogen. In plotting theoretical weight curves, the shaded circles indicate actual weight; crosses indicate protoplasm (nitrogen); open triangles indicate protoplasm plus extracellular fluid (sodium); the shaded triangles indicate theoretical weight derived from nitrogen, sodium, and potassium. 


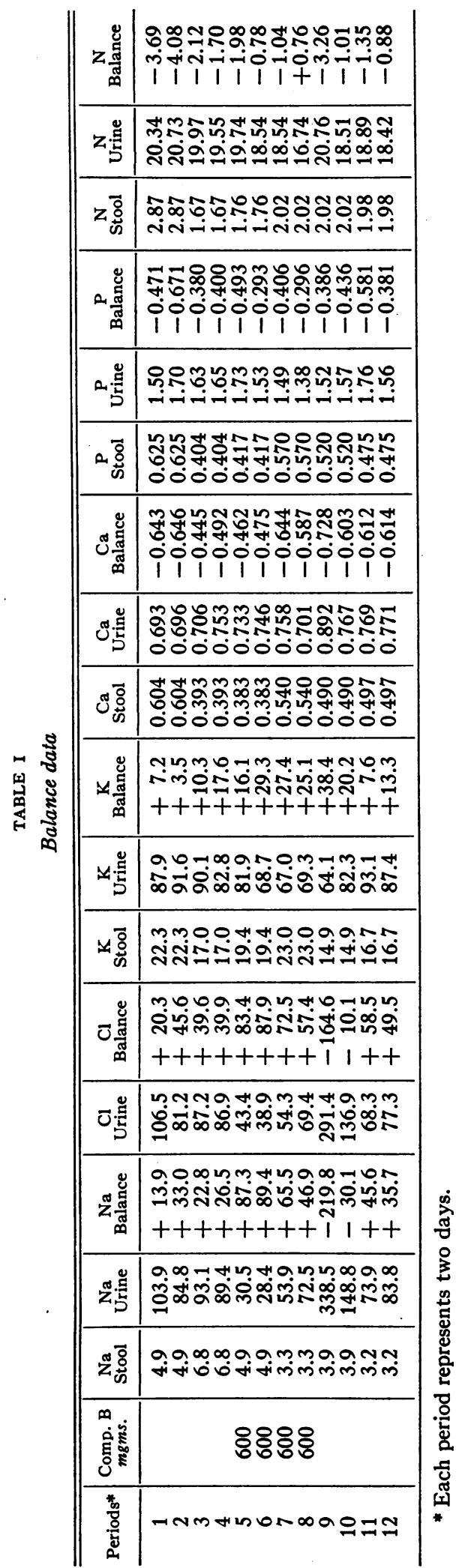

ness suddenly increased in both shoulders. Corticosterone was begun on the twenty-first hospital day and continued for eight days. During the first four days of hormone therapy, there was no change in subjective or objective clinical manifestations. On the fifth and sixth days of therapy, the shoulder pain that had appeared two days before treatment subsided, and stiffness and pain generally decreased. On the seventh day, general stiffness and pain and swelling of the midphalangeal joints and wrists increased, and moderate effusions appeared in both knees. His clinical status was unchanged on the eighth day. During the first two days following treatment, knee swelling increased. $\mathrm{He}$ was discharged nine days after treatment without further changes.

\section{Laboratory Results}

The corrected erythrocyte sedimentation rate (Figure 1) was 0.60 millimeter per minute on two occasions during a two-week period prior to therapy. It ranged between 0.43 and 0.50 millimeter per minute during therapy and between 0.72 and 0.83 millimeter per minute during the recovery period. Synovial fluid was aspirated on the second post-treatment day. Its white cell count was 7,275 cells per cubic millimeter with 71 per cent polymorphonuclear leukocytes, 10 per cent lymphocytes, and 19 per cent monocytes. The mucin precipitated in a soft, stringy clump, leaving a slightly cloudy solution. The fasting synovial fluid sugar was 22 milligrams per cent, while the serum sugar was 61 milligrams per cent. The number of circulating eosinophils were lower during treatment, but a striking decrease appeared in only one of seven determinations (Figure 1).

\section{Results of Balance Studies}

Balance data are shown graphically in Figure 1 and tabulated in Table I. Diet values are shown in Table II.

TABLE II

Results of diet analysis*

\begin{tabular}{lr}
\hline \hline Sodium & $122.7 \mathrm{mEq}$. \\
Chloride & $126.8 \mathrm{mEq}$. \\
Potassium & $117.4 \mathrm{mEq}$. \\
Calcium & $654.0 \mathrm{mgms}$. \\
Phosphorus & $1.65 \mathrm{gms}$. \\
Nitrogen & $19.52 \mathrm{gms}$.
\end{tabular}

* Values represent two-day periods. 
TABLE III

Theoretical and actual phosphorus balances

\begin{tabular}{ccc}
\hline \hline Periods & $\begin{array}{c}\text { Theoretical } \\
\text { P balance }\end{array}$ & $\begin{array}{c}\text { Actual } \\
\text { P balance }\end{array}$ \\
\hline 1 & -0.539 & -0.471 \\
2 & -0.568 & -0.671 \\
3 & -0.344 & -0.380 \\
4 & -0.337 & -0.400 \\
5 & -0.342 & -0.493 \\
6 & -0.266 & -0.293 \\
7 & -0.360 & -0.406 \\
8 & -0.211 & -0.296 \\
9 & -0.548 & -0.386 \\
10 & -0.339 & -0.436 \\
11 & -0.366 & -0.581 \\
12 & -0.335 & -0.381 \\
\hline
\end{tabular}

The following scheme of illustrating actual balance data is used. Intake is plotted downward from a horizontal base-line marked zero, and stool and urine values are plotted upward from the intake line. Shaded areas above the base-line indicate negative balances and clear areas below the base-line indicate positive balances. The ordinate scales for nitrogen, phosphorus, and potassium are chosen on the basis of ratios for protoplasm $(9,19)$ and bone $(9,20)$, so that phosphorus balance should equal the sum of the corresponding areas for nitrogen and calcium balances, and potassium balance should equal nitrogen balance. Ordinate scales for sodium and chloride are the same as potassium.

Cumulative electrolyte balances, shown also in Figure 1, were derived by subtracting the control averages from the actual balances and adding the results of each period to the preceding period. The metabolic findings were as follows:

(a) Nitrogen metabolism. During control periods, the patient was in negative nitrogen balance. Slight nitrogen retention occurred during the administration of corticosterone. Nitrogen excretion increased for two days following treatment, then decreased. Changes in nitrogen excretion thus correlated poorly with administration of the hormone.

(b) Phosphorus metabolism. Phosphorus excretion decreased slightly during treatment and increased subsequent to treatment. The theoretical phosphorus balances, derived from calcium balances (calcium balance $\div 2.23$ ) (20), and nitrogen balances (nitrogen balance $\div$ 14.7) (19), were in good agreement with actual phosphorus balances, although throughout the experiment ac- tual phosphorus loss exceeded the theoretical phosphorus loss (Table III). Serum phosphorus increased during therapy.

(c) Calcium metabolism. Urinary calcium remained almost constant during therapy but increased for two days following therapy during a period of diuresis.

(d) Potassium metabolism. Potassium retention during treatment is shown in both actual and cumulative balance data. Potassium gained during treatment was not lost during the recovery period and could be in part due to sweat losses.

Cumulative potassium balances were also derived after correcting actual potassium balances for actual nitrogen balances (potassium balancenitrogen balance $\times 2.7)(21)$, to estimate potassium gained or lost as intracellular fluid and/or glycogen (9). Although these derived data revealed potassium being retained both in relation to protoplasm and intracellular fluid, or glycogen, some potassium may have been lost in sweat since perspiration noticeably increased during treatment. Serum potassium decreased slightly during therapy.

(e) Sodium and chloride metabolism. Actual and cumulative balance data revealed sodium retention during therapy and loss during recovery periods. Cumulative data revealed that the posttreatment sodium loss was greater than the gain during treatment. Chloride balances were almost identical to sodium balances. Serum sodium and chloride increased during therapy, but serum chlo-

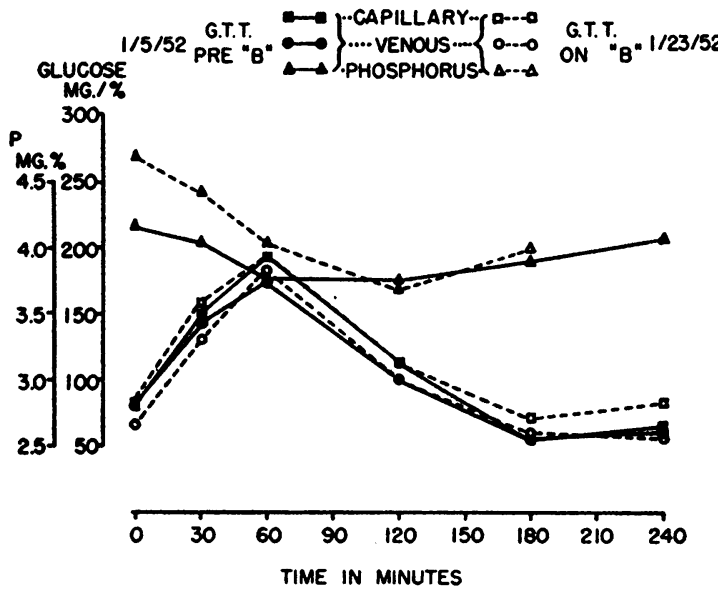

Fig. 2. Arterial and Venous Glucose Tolerance Curves with Serum Phosphorus Values 
ride did not exceed one unusually high control value.

(f) Body weight. Changes in actual and theoretical weight, calculated from potassium balances (intracellular fluid), sodium balances (extracellular fluid), and nitrogen balances (protoplasm), by methods described by Reifenstein, Albright, and Wells (9), are shown in Figure 1. Theoretical weight increases, derived from potassium and sodium balances, were greater than actual increases. Sweating, which was noticeably increased during therapy, could account for this discrepancy. The actual weight increase on therapy seemed to relate entirely to fluid retention.

(g) 17 Ketosteroid excretion. Urinary 17 ketosteroid values (shown graphically in Figure 1) decreased slightly during treatment and recovery periods. These changes were not considered significant.

(h) Carbohydrate tolerance. Arterial and venous glucose tolerance curves during therapy (Figure 2) were not significantly different from control curves. Serum phosphorus decreases following glucose ingestion were approximately the same before and during treatment. There was no glycosuria in daily specimens or during glucose tolerance studies.

\section{DISCUSSION}

The appearance of knee involvement with effusions suggested an actual increase in the activity of the rheumatoid arthritis during treatment with corticosterone. Since the knee effusions continued beyond the period of post-treatment diuresis of sodium, they could not be attributed to sodium retention and probably represented a fluctuation in the natural course of the disease. Thus it would appear that corticosterone had neither a favorable nor unfavorable effect on the arthritis.

Retention of sodium and chloride induced by corticosterone in this experiment agreed with the observations of Conn, Fajans, Louis, and Johnson (7). The potassium retention was unexpected and there was no comparable potassium loss during recovery periods. There was some correlation between potassium retention and nitrogen retention which also continued through the recovery periods. All potassium retained could not be explained by nitrogen retention and the unexplained potassium gained could be due to the deposition of glycogen or, possibly, losses in sweat. In favor of the latter explanation are slight discrepancies in the theoretical and actual weight curves and the cumulative loss of potassium unrelated to nitrogen through the recovery period.

Conn, Fajans, Louis, and Johnson have demonstrated that corticosterone prevents hypoglycemia, decreases glucose tolerance, and increases insulin tolerance (7). Similar effects on human carbohydrate metabolism, particularly in patients with Addison's disease, had also been observed by Thorn and Forsham (6). The negative data on carbohydrate activity described in this paper do not invalidate these observations since patients with adrenal insufficiency are more sensitive subjects for evaluation of this metabolic effect.

Like corticosterone, dehydrocorticosterone also has been found to have some carbohydrate activity (6) but no ameliorative effects in rheumatoid arthritis (22), and studies thus far with these two hormones suggest that carbohydrate activity does not endow a steroid with antirheumatic properties. Conversely, no steroid has been found as yet to have antirheumatic properties that does not have carbohydrate activity. Also, cortisone and hydrocortisone are more potent carbohydrate active steroids than corticosterone and dehydrocorticosterone (6), and it is possible that the administration of larger doses of the latter two steroids would favorably influence rheumatoid arthritis. Cumulative evidence suggests that only corticosteroids with active groups at both the carbon 11 and 17 positions have antirheumatic effects.

\section{SUMMARY AND CONCLUSIONS}

The administration of corticosterone to one patient with rheumatoid arthritis caused marked sodium and chloride retention but had no antirheumatic effects. No significant changes in carbohydrate tolerance or calcium and nitrogen excretion were evident from the administration of this hormone. Although the data indicated potassium retention, it is doubted that it was a definite hormone effect.

\section{ACKNÖWLEDGMENTS}

The authors are indebted to Dr. H. F. Hailman of the Upjohn Company for providing the corticosterone used 
in this study, also to Dr. Lewis L. Engel and the Huntington Memorial Laboratories for the 17 ketosteroid determinations, and to Miss Janet Appleton and Miss Katherine Brine for technical assistance.

\section{REFERENCES}

1. DeFremery, P., Laqueur, E., Reichstein, T., Spanhoff, R. W., and Uyldert, I. E., Corticosteron, a crystallized compound with the biological activity of the adrenal-cortical hormone. Nature, 1937, 139, 26.

2. Mason, H. L., Hoehn, W. M., McKenzie, B. F., and Kendall, E. C., Chemical studies of the suprarenal cortex. III. The structures of compounds A, B, and H. J. Biol. Chem., 1937, 120, 719.

3. Hechter, O., Zaffaroni, A., Jacobsen, R. P., Levy, H., Jeanloz, R., Schenker, V., and Pincus G., The nature and the biogenesis of the adrenal secretory product. Recent Progress in Hormone Research, $1951,6,215$.

4. Pincus, G., Hechter, O., and Zaffaroni, A., The effect of ACTH upon steroidogenesis by the isolated perfused adrenal gland. Proceedings of the 2nd Clinical ACTH Conference, J. R. Mote, ed., 1951, The Blakiston Company, Philadelphia, Vol. I, p. 40.

5. Reich, H., Nelson, D. H., and Zaffaroni, A., Isolation of 17-hydroxycorticosterone from blood obtained from adrenal veins of dogs. J. Biol. Chem., 1950, $187,411$.

6. Thorn, G. W., and Forsham, P. H., Metabolic changes in man following adrenal and pituitary hormone administration. Recent Progress in Hormone Research, 1949, 4, 229.

7. Conn, J. W., Fajans, S. S., Louis, L. H., and Johnson, B., Metabolic and clinical effects of corticosterone (Compound B) in man. Proceedings of the 2nd Clinical ACTH Conference, J. R. Mote, ed., 1951, The Blakiston Company, Philadelphia, Vol. I, p. 221.

8. Robinson, W. D., Discussion of : Metabolic and clinical effects of corticosterone (Compound B) in man. Proceedings of the 2nd Clinical ACTH Conference, J. R. Mote, ed., 1951, The Blakiston Company, Philadelphia, Vol. I, p. 230.

9. Reifenstein, E. C., Jr., Albright, F., and Wells, S. L., The accumulation, interpretation, and presentation of data pertaining to metabolic balances, notably those of calcium, phosphorus, and nitrogen. J. Clin.
Endocrinol., 1945, 5, 367, Correction, idem, ibid., 1946, 6, 232.

10. Wallace, W. M., Holliday, M., Cushman, M., and Elkinton, J. R., The application of the internal standard flame photometer to the analysis of biological material. J. Lab. \& Clin. Med., 1951, 37, 621.

11. Wilson, D. W., and Ball, E. G., A study of the estimation of chloride in blood and serum. J. Biol. Chem., 1928, 79, 221.

12. Pregl, F., Quantitative Organic Micro-analysis Based on the Methods of Fritz Preg1, 5th English Edition, completely rev. and edited by Julius Grant, The Blakiston Company, Philadelphia, 1951.

13. Fiske, C. H., and Logan, M. A., Determination of calcium by alkalimetric titration. II. The precipitation of calcium in the presence of magnesium, phosphate, and sulfate, with applications to the analysis of urine. J. Biol. Chem., 1931, 93, 211.

14. Fiske, C. H., and Subbarow, Y., The colorimetric determination of phosphorus. J. Biol. Chem., 1925, 66, 375.

15. Nathanson, I. T., and Wilson, H., Factors affecting colorimetric urinary 17-ketosteroid excretion. Endocrinology, 1943, 33, 189.

16. Rourke, M. D., and Ernstene, A. C., A method for correcting the erythrocyte sedimentation rate for variations in the cell volume percentage of blood. J. Clin. Invest., 1930, 8, 545.

17. Nelson, N., A photometric adaptation of the Somogyi method for the determination of glucose. J. Biol. Chem., 1944, 153, 375.

18. Randolph, T. G., Blood studies in allergy. I. The direct counting chamber determination of eosinophils in propylene glycol aqueous stains. J. Allergy, 1944, 15, 89.

19. Benedict, F. G., A study of prolonged fasting. Publication No. 203 of The Carnegie Institution of Washington, 1915.

20. Shohl, A. T., Mineral Metabolism. American Chemical Society. Monographic Series (No. 82). Reinhold Publishing Corp., New York, 1939.

21. Harrison, H. E., Darrow, D. C., and Yannet, H., The total electrolyte content of animals and its probable relation to the distribution of body water. J. Biol. Chem., 1936, 113, 515.

22. Hench, P. S., The reversibility of certain rheumatic and non-rheumatic conditions by the use of cortisone or of the pituitary adrenocorticotropic hormone. Ann. Int. Med., 1952, 36, 1. 